\title{
Null effects of exposure duration and heterogeneity of difference on the same-different disparity in letter matching
}

\author{
ROBERT W. PROCTOR and K. VENKATA RAO \\ Auburn University, Auburn, Alabama
}

\begin{abstract}
The rechecking and external-noise postulates of Krueger's (1978) noisy-operator theory were examined in three letter-matching experiments. Rechecking was tested by varying exposure duration, both without (Experiment 1) and with (Experiment 2) a subsequent noise mask. Predictions of a decreased same-different reaction time disparity and an increase in false different errors at brief exposures were not borne out. The external-noise postulate was tested by varying the degree of heterogeneity of difference between letter sets. The prediction of a smaller samedifferent reaction time disparity for the more heterogeneous letter set was not obtained. Thus, the results did not support internal noise as the basis of the same-different disparity, but were more consistent with response-inhibition accounts.
\end{abstract}

When subjects judge pairs of letters to be same or different, correct different responses are usually slower than correct same responses. In recent years, several researchers have provided comprehensive accounts of this same-different disparity (C. W. Eriksen, O'Hara, \& B. A. Eriksen, 1982; Krueger, 1978; Proctor, 1981). According to C. W. Eriksen et al. and Proctor, inhibitory processes at either the overt response level or the internal recognition level account for the relative slowness of different judgments. Krueger, on the other hand, attributes the samedifferent disparity to noise internal to the perceiver. This internal noise produces spurious featural differences for same pairs, which necessitates additional rechecking of different pairs.

Proctor and Rao (1983) evaluated the internalnoise principle and argued that it is most likely not the basis for the same-different disparity because it relies on several questionable assumptions. The present article is the empirical counterpart of the previous evaluation of the internal-noise principle. Two critical assumptions that underlie the principle, the postulates of discrete rechecking and external noise, are subjected to direct experimental test. Secondarily, implications of the results for the inhibition principle are considered.

\section{Rechecking}

Krueger's (1978) noisy-operator theory considers that matching decisions are based on a difference

We would like to thank Terry Ellsbury, Timothy Hartford, Kirby Kepner, and Drew Warman for assistance in conducting these experiments. Requests for reprints should be sent to Robert W. Proctor, Department of Psychology, Auburn University, Auburn, Alabama 36849. count (number of featural mismatches). Internal noise acts to perturbate features such that both same and different pairs will have distributions of difference counts. When the difference count on a trial falls below a low criterion or above a high criterion, the subject responds same or different, respectively. When the count is intermediate to the criteria, rechecking occurs.

On the average, different pairs receive more rechecking than same pairs. The reason for this lies in the shape of the distribution of difference counts for same pairs. Because the true count for these pairs is zero, the distribution will have a positive skew. This positive skew undermines the different distribution, such that with equivalent likelihood criteria, the percentage of the different distribution falling within the indeterminant region is greater than the percentage of the same distribution that does so (see Krueger, 1978, Figure 2, for a graphical representation of the distributions and criteria for responding).

Thus, the noisy-operator theory attributes the additional time for different responses relative to same responses to greater rechecking performed for different pairs. According to Krueger (1978), this rechecking involves additional discrete looks or passes, following an initial comparison pass, each of which "might entail a true double take, with both the encoding of the stimulus, if still available, and the comparison operation being performed again" (p. 285). For the specific model that he fit to data, the duration of each discrete pass was set at $200 \mathrm{msec}$.

One implication of the discrete-rechecking assumption is that exposure duration should be a critical determinant of the magnitude of the same-different reaction time disparity. That is, rechecking should be effective only if the stimuli are present so that a com- 
plete reencoding and comparison can occur. Proctor and Rao (1983) noted that in four of the six sets of data that Krueger (1978) fit to the noisy-operator theory, the exposure duration of the second item of a sequentially presented pair was $200 \mathrm{msec}$ or less. That is, the exposure durations were seemingly too brief to allow effective rechecking to occur.

Experiments 1 and 2 of the present article provide a more direct test of the rechecking notion by varying the exposure duration of the letters. If rechecking does provide the basis for the same-different disparity, the disparity should be greater at longer exposure durations. Moreover, because of the lesser rechecking at short exposure durations, the overall proportion of errors should be greater than at longer exposure durations, with this increase in errors occurring primarily for false different responses. ${ }^{1}$

\section{External Noise}

The second critical assumption of the noisy-operator theory deals with the influence of external noise. External noise refers to variability in the number of featural differences for the various different pairs. Krueger (1978) assumed that the number of featural differences was equivalent for all pairs (homogeneity of difference). Proctor and Rao (1983) presented evidence indicating that this assumption is unjustified, even for small, relatively homogeneous letter sets. The homogeneity-of-difference assumption is critical to the prediction of the same-different disparity because heterogeneity of difference will tend to counteract the benefit for same pairs that is attributable to internal noise (Krueger, 1978).

Given that different letter pairs vary in terms of the number of featural differences, the amount of heterogeneity of difference can be varied between letter sets. The rather straightforward prediction of the noisy-operator theory is that the same-different disparity should be larger in the situation with less heterogeneity of difference. Experiment 3 tested this prediction.

\section{EXPERIMENT 1}

Experiment 1 tested the rechecking postulate by varying the exposure duration of letter pairs. Stimuli were presented simultaneously because the evidence most clearly indicates that simultaneous judgments are based on the physical visual information and problems concerning the relative durations of the two stimuli that are inherent in sequential presentation are avoided. Four different exposure durations of 50, 100,200 , and $400 \mathrm{msec}$ were employed.

\section{Method}

Apparatus. The stimuli were presented in a two-field tachistoscope (Gerbrands, Model T-AB), with stimulus and interval durations controlled by the tachistoscope's control unit. Luminances of the white backgrounds in both fields were set at approximately $3 \mathrm{~cd} / \mathrm{m}^{2}$, as measured by a Tektronix $\mathrm{J} 16$ digital photometer. Responses were made by pressing one of two microswitches positioned under the index finger of each hand. For half of the subjects, the left-hand key was for the same response and the righthand key for the different response; for the other half of the subjects, this pairing was reversed. Reaction time was recorded to the nearest millisecond on digital counters.

Materials and Design. Stimuli for the tasks were pairs of uppercase letters from the set B, D, T, F, S, X. The letters were 14-point Helvetica medium (Prestype 1321-18 CLN) that covered a visual angle of approximately .38 deg in width and $.45 \mathrm{deg}$ in height. All letters were black and were mounted in pairs on white index cards. The letters were placed side by side horizontally, with $1.15-$ deg separation between them. A lighted blank field with a small, dark fixation dot remained on at all times other than when the letters were presented. The fixation dot was level with the bases of the letters, equidistant between them.

Within a session, four blocks of 60 trials each (30 same and 30 different pairs) were presented. Within a block, each of the 6 possible same pairs occurred five times and each of the 30 possible different pairs occurred once. Four exposure durations $(50,100$, 200 , and $400 \mathrm{msec}$ ) were manipulated between blocks. Thus, each subject was tested in distinct blocks at all four exposure durations, with the order of the blocks counterbalanced across subjects.

Subjects and Procedure. The subjects were 12 students who were enrolled in undergraduate psychology classes and who participated for extra credit. Each subject participated in two 45-min sessions on successive days, with the order of the four exposureduration blocks being identical for both sessions. Six practice trials were presented before each block.

Each trial began with presentation of a 500 -msec warning tone. Five hundred milliseconds after the offset of the tone, the two letters were presented for the appropriate duration. The subjects were instructed to respond same or different as rapidly as possibly without making many errors. They were also told that half of the pairs would be same and half would be different.

\section{Results}

Reaction time data. Mean reaction times for the correct same and different respones were obtained for each subject as a function of exposure duration and session. The means of these data, collapsed across sessions, are shown in Table 1.

A three-factor analysis of variance revealed only two significant effects, the main effect for type of pair $[F(1,11)=18.72, p<.005]$ and the interaction of type $\times$ sessions $[F(1,11)=6.00, p<.05]$. These effects indicate that same judgments were faster than different judgments and that this disparity was somewhat greater in the first session ( $26 \mathrm{msec}$ ) than in the

Table 1

Mean Reaction Times (in Milliseconds) and Proportion of Errors (PE) for Experiment 1

\begin{tabular}{|c|c|c|c|c|}
\hline \multirow{3}{*}{$\begin{array}{l}\text { Exposure } \\
\text { Duration }\end{array}$} & \multicolumn{4}{|c|}{ Type of Pair } \\
\hline & \multicolumn{2}{|c|}{ Same } & \multicolumn{2}{|c|}{ Different } \\
\hline & RT & PE & RT & PE \\
\hline 50 & 412 & .022 & 437 & .022 \\
\hline 100 & 415 & .024 & 426 & .019 \\
\hline 200 & 419 & .014 & 440 & .024 \\
\hline 400 & 422 & .018 & 445 & .018 \\
\hline
\end{tabular}


second (14 msec). All other $F$ ratios were approximately equal to 1.0 .

Of particular importance was the fact that none of the effects involving exposure duration approached significance. Thus, although the same-different disparity was obtained, it did not vary systematically in the manner predicted by the rechecking postulate.

Error data. The mean proportion of errors for each condition is also shown in Table 1. An analysis of variance showed no significant effects, with only the $F$ ratio for the type of pair $\times$ exposure duration interaction deviating greatly from $1.0[\mathrm{~F}(1,11)=3.88$, $p>.05]$. Because there is no systematic tendency toward relatively greater (or fewer) false different responses as a function of exposure duration, this trend is apparently meaningless. Thus, the error data indicate no systematic effect of exposure duration on the overall level or pattern of errors. In addition, there was no predominance of false different responses, as is often obtained (Krueger, 1978).

\section{Discussion}

Exposure duration does not have any reliable effect on the same-different disparity in reaction time or on the relative proportion of errors to same and different pairs. Both of these findings are counter to the hypothesis that the disparity is attributable to rechecking of different pairs. If such were the case, the magnitude of the reaction time disparity should have decreased with exposure duration and the relative proportion of false different responses should have increased.

It might be argued that the persistence of a sensory image for a few hundred milliseconds would allow for rechecking, thus overriding the limitation of physical exposure duration. There are, however, two problems with this argument. First, the sensory visual image degrades over time, making the quality of information available for rechecking of poor quality. Second, accepting Krueger's proposed duration of $200 \mathrm{msec}$ for each cycle, even sensory persistence of 250-300 msec would not be sufficient to allow full rechecking at the 50-msec exposure duration. Thus, the sensory-persistence argument has problems in explaining the data from Experiment 1 . However, in order to deal more directly with this possibility, a second experiment was conducted.

\section{EXPERIMENT 2}

Effective exposure duration can be limited much more closely to the physical exposure duration when a visual noise mask occurs at the offset of the stimuli. Thus, Experiment 2 employed a noise mask that came on immediately at the offset of the target letters. In Experiment 2, as in Experiment 1, our primary concern was to prevent rechecking by limiting exposure duration. Because a noise mask can also interfere with the initial encoding of briefly presented targets (e.g., C. W. Eriksen, 1980; Schultz \& C. W. Eriksen, 1977), we wanted to limit the exposure durations examined to ones of sufficient duration to allow accurate encoding. Krueger (1978) set the duration for the initial pass at $200 \mathrm{msec}$. Because integration of the mask with the target items before they are completely encoded can occur at briefer durations (Schultz \& C. W. Eriksen, 1977), this 200-msec duration seems an appropriate minimum. Thus, in Experiment 2, only the two durations of $200 \mathrm{msec}$ and $400 \mathrm{msec}$ were employed. The prediction of the rechecking postulate is that the same-different disparity should be of smaller magnitude for the 200 -msec exposure than for the 400 -msec exposure.

\section{Method}

Subjects, Materials, and Design. The subjects were 12 psychology undergraduates who participated in a single experimental session for extra credit. The letter stimuli were the same as in Experiment 1 . The subjects received two blocks of 60 trials at each of the two exposure durations ( 200 and $400 \mathrm{msec}$ ), with the blocks presented in an ABBA format and counterbalanced across subjects. A random noise mask (Artype HR 4082) composed of black squiggles on a white background was employed. The mask was centered in the visual field, subtending a visual angle of approximately $14 \mathrm{deg}$ in width and $9.5 \mathrm{deg}$ in height. Proctor and Fagnani (1978) have previously shown this particular mask to be effective at masking briefly exposed target letters (see Footnote 3 of their article).

Procedure. The procedure was similar to the one used in Experiment 1 , with the following differences. Because the apparatus was a two-field tachistoscope, with one field required for the letters and one for the mask, it was not possible to have a lighted preexposure field. Therefore, the subjects were instructed to fixate the center of the dark field. The procedure was then the same as Experiment 1, with the noise mask occurring for $1 \mathrm{sec}$ at the offset of the letters.

\section{Results and Discussion}

Reaction time data. Mean reaction times were obtained for the correct responses of each subject. The means of these data are shown in Table 2.

An analysis of variance showed only a significant main effect for type of pair $[F(1,11)=5.31, p<.05]$. Thus, the same-different disparity was again obtained. Reaction times tended to be faster with the 400-msec exposure than with the 200-msec exposure, although this did not achieve significance $[F(1,11)=$

Table 2

Mean Reaction Times (in Milliseconds) and Proportion of Errors (PE) for Experiment 2

\begin{tabular}{cccccc} 
& \multicolumn{4}{c}{ Type of Pair } \\
\cline { 2 - 5 } Exposure & \multicolumn{2}{c}{ Same } & & \multicolumn{2}{c}{ Different } \\
\cline { 2 - 5 } \cline { 5 - 6 } Duration & RT & PE & & RT & PE \\
\hline 200 & 514 & .035 & & 528 & .028 \\
400 & 501 & .018 & & 517 & .028 \\
\hline
\end{tabular}


$3.84, p>.05]$. As indicated by the lack of a significant interaction for type of pair $\times$ exposure duration $[F<1.0]$, exposure duration had no reliable influence on the magnitude of the same-different disparity. The disparity was 14 and $16 \mathrm{msec}$ for the 200and 400-msec exposure conditions, respectively.

The magnitude of the same-different disparity obtained in the present experiment was approximately $5 \mathrm{msec}$ less than that obtained in Experiment 1. Thus, it might be argued that although the mask did not differentially decrease the magnitude of the disparity for the two exposure durations, it did decrease it overall. We had previously conducted an experiment (that is not reported in detail here because of the inclusion of extraneous conditions) in which data were collected from 12 subjects viewing both blank and masked poststimulus fields. There was no difference in magnitudes of the same-different disparity for the two situations [ $F<1.0]$. In fact, in that experiment, the disparity in the masked condition was nonsignificantly greater at the 200-msec exposure duration than at the 400 -msec one, again running counter to the rechecking postulate.

Error data. The proportion of errors are presented in Table 2. As in Experiment 1, no effects were reliable [Fs $\approx 1.0$ ]. Thus, neither the finding of more numerous false different responses nor an interaction with exposure duration was obtained.

Despite the lack of a reliable interaction, the mean data are in the direction predicted by the rechecking postulate. The proportion of false different errors at $200 \mathrm{msec}$ is roughly twice that at $\mathbf{4 0 0} \mathrm{msec}$, with the proportion of false same errors being constant. Examination of the individual subject data clearly indicated why there was no sign of an effect in the statistical analysis. The high proportion of false different errors at $200 \mathrm{msec}$ is attributable entirely to two subjects. In fact, more subjects show greater false same errors at $200 \mathrm{msec}$ than show greater false different errors. Thus, the error data offer no support for the predictions of the rechecking postulate.

\section{EXPERIMENT 3}

Whereas Experiments 1 and 2 examined implications of the rechecking postulate of the noisy-operator theory, Experiment 3 tested the external noise postulate. The external-noise postulate states that heterogeneity of difference among the various different pairs (i.e., differences in amount of featural overlap) will tend to counteract the effect of internal noise. That is, external noise acts to increase the amount of rechecking necessary for same pairs relative to that for different pairs. Krueger (1979) attributes the faster different judgments obtained with unidimensional tonal stimuli to the predominance of external noise in that situation.

For letter pairs, Krueger (1978) assumed homoge- neity of difference, that is, that all different pairs differ by the same number of features. Proctor and Rao (1983) noted that the assumption of homogeneity of difference for letter pairs is incorrect and, furthermore, does not even seem to be a reasonable approximation of the state of affairs. Tachistoscopic recognition studies and the distinctive feature systems based on them clearly show relatively large heterogeneity of difference (Gibson, 1969; Gilmore, Hersh, Caramazza, \& Griffin, 1979; Keren \& Baggen, 1981). Similarly, the geometric representational system employed by Krueger (1978) also shows substantial heterogeneity of difference. Perhaps the most damaging evidence, however, is that different reaction times are clearly influenced by this heterogeneity of difference. With simultaneous or immediately successive letter presentation, different response latencies increase as a function of visual similarity (Clement \& Carpenter, 1970; Thorson, Hochhaus, \& Stanners, 1976; Gibson, Osser, Schiff, \& Smith, Note 1).

Given that heterogeneity of difference does in fact exist between pairs of letters, it is possible to select sets that differ in the relative degree of heterogeneity. Experiment 3 examined two such sets. The obvious prediction of the noisy-operator theory is that the same-different disparity should be of greater magnitude for the letter set that has less heterogeneity of difference.

\section{Method}

Subjects. Twenty-four undergraduate psychology students participated in the experiment for extra credit. Each subject participated in two sessions.

Apparatus, Materials, and Design. The apparatus was the same as that used in the previous two experiments. Two distinct letter sets were employed to construct stimuli: A, E, N, T, and E, P, R, $W$. These letter sets were chosen on the basis of the extent of the heterogeneity of differences between letter pairs within the set, with the average difference held approximately equal. Table 3 presents data from two confusion matrices (Gilmore et al., 1979; Townsend, 1971) and four distinctive feature systems (Geyer \& DeWald, 1973; Gibson, 1969; Keren \& Baggen, 1981; Lindsay \& Norman, 1977). These studies, and all similar ones of which we are aware, consistently show that heterogeneity of difference is smaller for the A, E, N, T set than for the E, P, R, W set (from this point, the former set will be referred to as the homogeneous set, whereas the latter will be referred to as the heterogeneous set). That is, the variability in number of featural differences and proportion of confusions (as indicated by the standard deviation) is less for the former set than for the latter.

Within each letter set, all possible combinations of same and different pairs were constructed. Blocks of 48 trials were constructed for each set such that within each block there were 24 same pairs (six pairs for each of the four letters) and 24 different pairs (two of each of the 12 pairings of the two letters that are possible when spatial position-left or right-is taken into account). Positioning of the two letters on the stimulus cards was the same as in Experiments 1 and 2.

Letter set was a between-subjects variable. Within each of the two sessions, the subjects received four blocks of trials from the appropriate set, with the first block preceded by 10 practice trials and the others by two each. The procedure for each trial was the same as in Experiment 1, with exposure duration held constant at $500 \mathrm{msec}$. 
Table 3

Number of Featural Differences and Average Proportion of Confusion Errors for the Two Letter Sets Tested in Experiment 3

\begin{tabular}{|c|c|c|c|c|c|c|}
\hline & \multicolumn{4}{|c|}{ Distinctive Feature Systems } & \multicolumn{2}{|c|}{ Confusion Matrices } \\
\hline & $\begin{array}{c}\text { Geyer \& } \\
\text { Dewald (1973) }\end{array}$ & $\begin{array}{c}\text { Gibson } \\
\text { (1969) }\end{array}$ & $\begin{array}{c}\text { Keren \& } \\
\text { Baggen (1981) }\end{array}$ & $\begin{array}{c}\text { Lindsay \& } \\
\text { Norman (1977) }\end{array}$ & $\begin{array}{c}\text { Gilmore } \\
\text { et al. (1979) }\end{array}$ & $\begin{array}{c}\text { Townsend } \\
\text { (1971) }\end{array}$ \\
\hline \multicolumn{7}{|c|}{ Homogeneous Set: A, E, N, T } \\
\hline $\mathrm{AE}$ & 8 & 6 & 7 & 12 & .004 & .010 \\
\hline AN & 10 & 5 & 5 & 5 & .042 & .023 \\
\hline AT & 7 & 4 & 5 & 8 & .003 & .018 \\
\hline EN & 8 & 8 & 8 & 11 & .004 & .003 \\
\hline ET & 5 & 2 & 6 & 4 & .006 & .038 \\
\hline NT & 5 & 5 & 6 & 7 & .003 & .025 \\
\hline Mean & 7.17 & 5.00 & 6.17 & 7.83 & .010 & .020 \\
\hline SD & 1.77 & 1.83 & 1.07 & 2.91 & .014 & .011 \\
\hline \multicolumn{7}{|c|}{ Heterogeneous Set: E, P, R, W } \\
\hline EP & 6 & 6 & 4 & 3 & .014 & .020 \\
\hline ER & 7 & 7 & 6 & 4 & .035 & .008 \\
\hline EW & 11 & 6 & 8 & 15 & .004 & .000 \\
\hline PR & 3 & 1 & 2 & 1 & .076 & .065 \\
\hline PW & 7 & 8 & 8 & 14 & .006 & .013 \\
\hline RW & 8 & 7 & 10 & 13 & .033 & .010 \\
\hline Mean & 7.00 & 5.83 & 6.33 & 8.33 & .028 & .019 \\
\hline SD & 2.38 & 2.27 & 2.68 & 5.76 & .025 & .021 \\
\hline
\end{tabular}

\section{Results and Discussion}

Internal validity of the heterogeneity manipulation. Before examining the mean same and different reaction times for the two letter sets, it is important to establish that the heterogeneity-of-difference manipulation was effective. As indicated previously, numerous investigators have shown that different reaction time varies as a function of similarity, and thus the mean reaction times for the respective different pairs within the homogeneous set should show less variability than for those in the heterogeneous set.

The mean reaction times for each pair of letters (disregarding spatial position) are shown in Table 4. A number of measures confirmed the expectation that variability between pairs would be less in the homogeneous set. The range of mean reaction times for the pairwise different combinations of $E, P, R$, and $W$ was 72 and $79 \mathrm{msec}$ for Sessions 1 and 2, respectively, and 28 and $27 \mathrm{msec}$ for combinations of $A, E, N$, and T. The standard deviations for these means were 26.25 and 26.60 for the heterogeneous set in Sessions 1 and 2, and 11.38 and 9.86 for the homogeneous set. Standard deviations of the mean reaction times for each subject were also calculated and submitted to an analysis of variance. The analysis confirmed statistically that the mean reaction times to different pairs from the homogeneous set varied less than those to pairs from the heterogeneous set $[F(1,11)=14.56, \mathrm{p}<.001]$, and that this difference between sets did not interact with sessions $[F(1,11)$ $=1.24, \mathrm{p}>.05]$. Thus, the evidence from the different reaction times in the present study confirms the effectiveness of the heterogeneity manipulation.

Mean same and different reaction times. The mean reaction time data collapsed across the particular pairs are presented in Table 5. An analysis of variance indicated that the usual same-different disparity was obtained $[F(1,11)=18.0, p<.005]$. In addition, the main effect for sessions was significant $[F(1,11)=$ $19.6, \mathrm{p}<.005$ ], as was the sessions $\times$ type of pair interaction $[F(1,11)=5.20, p<.05]$. These effects indicate that responses were faster overall in the second session and that the same-different disparity was less than in the first session. There was also a nonsignificant tendency for responses to be faster overall with the homogeneous letter set than with the heterogeneous one $[F(1,11)=1.78, p>.05]$.

The primary purpose of the present experiment was to determine whether the magnitude of the samedifferent disparity was less for the heterogeneous set than for the homogeneous set. Neither the two-way interaction of letter set $x$ type of pair nor the three-

Table 4

Mean Different Reaction Times for Each Letter Pair

\begin{tabular}{|c|c|c|c|c|c|c|c|c|c|c|c|c|c|}
\hline \multirow[b]{2}{*}{ Session } & \multicolumn{5}{|c|}{ Homogeneous Set } & \multirow[b]{2}{*}{ NT } & \multirow[b]{2}{*}{ Session } & \multicolumn{5}{|c|}{ Heterogeneous Set } & \multirow[b]{2}{*}{ RW } \\
\hline & $\mathbf{A E}$ & AN & $\mathrm{AT}$ & EN & ET & & & EP & ER & EW & PR & PW & \\
\hline $\begin{array}{l}1 \\
2\end{array}$ & $\begin{array}{l}480 \\
421\end{array}$ & $\begin{array}{l}483 \\
432\end{array}$ & $\begin{array}{l}479 \\
415\end{array}$ & $\begin{array}{l}466 \\
421\end{array}$ & $\begin{array}{l}483 \\
408\end{array}$ & $\begin{array}{l}455 \\
405\end{array}$ & $\begin{array}{l}1 \\
2\end{array}$ & $\begin{array}{l}472 \\
444\end{array}$ & $\begin{array}{l}492 \\
446\end{array}$ & $\begin{array}{l}496 \\
449\end{array}$ & $\begin{array}{l}532 \\
501\end{array}$ & $\begin{array}{l}468 \\
440\end{array}$ & $\begin{array}{l}460 \\
422\end{array}$ \\
\hline
\end{tabular}


Table 5

Mean Reaction Times (in Milliseconds) and Proportion of Errors (PE) for Same and Different Judgments in Experiment 3

\begin{tabular}{|c|c|c|c|c|c|c|c|c|}
\hline \multirow[b]{3}{*}{ Letter Set } & \multicolumn{4}{|c|}{ Session 1} & \multicolumn{4}{|c|}{ Session 2} \\
\hline & \multicolumn{2}{|c|}{ Same } & \multicolumn{2}{|c|}{ Different } & \multicolumn{2}{|c|}{ Same } & \multicolumn{2}{|c|}{ Different } \\
\hline & RT & $\mathrm{PE}$ & RT & $\mathrm{PE}$ & RT & $\mathrm{PE}$ & RT & $\mathrm{PE}$ \\
\hline Homogeneous & 445 & .022 & 473 & .016 & 399 & .016 & 418 & .017 \\
\hline Heterogeneous & 465 & .013 & 488 & .010 & 442 & .010 & 450 & .010 \\
\hline
\end{tabular}

way interaction of set $\times$ pair $\times$ sessions was significant [Fs $<1.0]$. Thus, there is no statistical support for the prediction that the same-different disparity would be of a greater magnitude for the former set than for the latter.

Despite the total lack of statistical support for the prediction, the mean data (see Table 5) showed a tendency in the predicted direction, particularly in the second session. The individual subject data were examined to determine why this tendency in the mean data did not produce even a trend in the inferential analysis. The reason was that the mean differences were attributable entirely to two subjects, one in each condition, who showed results that were highly deviant from those of anyone else. The subject in the heterogeneous condition showed a large reversal in the second session, with different responses being $40 \mathrm{msec}$ faster than same responses. The subject in the homogeneous condition showed an unusually high same-different disparity of $83 \mathrm{msec}$, with all other subjects showing disparities of considerably less magnitude. Exclusion of these subjects' data yielded mean disparities of 26 and $12 \mathrm{msec}$ for the heterogeneous set in Sessions 1 and 2, respectively, compared with 21 and $14 \mathrm{msec}$ for the homogeneous set.

In summary, the tendency apparent in the mean data toward a smaller same-different disparity for the heterogeneous condition has no statistical reliability and is apparently due to two aberrant subjects. This lack of effect is particularly striking when considered along with the earlier demonstration of the internal validity of the heterogeneity manipulation.

Error data. The error rates for the conditions are shown in Table 5 . The only significant effect was the main effect for letter set $[F(1,11)=5.18, p<.05]$. This effect reflects a higher error rate overall for the homogeneous set than for the heterogeneous set. Given the tendency toward faster responding with the homogeneous set, the error-rate difference apparently only reflects that subjects in the homogeneous condition were operating at a slightly lower speedaccuracy criterion.

\section{GENERAL DISCUSSION}

The present experiments tested two critical postulates of Krueger's (1978) noisy-operator theory, the postulates of rechecking and external noise. Neither postulate was supported by the tests.

\section{Rechecking}

Our evidence. The rechecking postulate was examined by varying the exposure duration. Because the noisy-operator theory attributes the same-different disparity in reaction time to additional rechecking (extra looks or passes) that occurs for different pairs, the disparity should decrease when exposure durations are too brief to allow adequate rechecking. This decrease in the reaction time disparity should be accompanied by an increase in the proportion of false different errors relative to the proportion of false same errors. Neither of these predictions was upheld in Experiment 1 when exposure duration was decreased from 400 to $50 \mathrm{msec}$.

A second test of the rechecking postulate was conducted in Experiment 2 by presenting a random noise mask at the offset of stimuli presented for either 200 or $400 \mathrm{msec}$. The logic of the experiment was that whereas the latter exposure duration should allow sufficient time for rechecking, the former should allow only sufficient time for an accurate initial encoding. Again, no reliable differences in the reaction time disparity or in the relative error rates were obtained, although there were slight, but completely nonsignificant, differences in the predicted direction.

The present experiments indicate that rechecking based on a reencoding of the sensory information is not the basis for the same-different disparity. They leave open the possibility of rechecking performed on a more abstract visual or conceptual code. However, the results are particularly damaging to the noisyoperator theory because of the emphasis that it places on internal noise. That is, if noise within the observer is acting to constantly degrade perceptual representations, rechecking based on these degraded representations would not be beneficial. Given the stress that the noisy-operator theory places on the harmful effects of internal noise, the theory remains internally consistent only if rechecking involves a reencoding of sensory information.

Krueger and Shapiro's (1982) evidence. In contrast with Experiments 1 and 2 of the present article, Krueger and Shapiro (1982) reported three experiments that they interpreted as supporting the noisy-operator 
theory and its rechecking postulate. The experiments involved situations in which subjects searched simultaneously or sequentially presented lists of same pairs for an odd different pair, or vice versa. The primary result that Krueger and Shapiro interpreted as supporting the noisy-operator theory was that misses of a target pair were higher for different lists (in which the odd pair was same), whereas false alarms were greater for same lists (although only with rapid serial presentation). The interpretation that they provided for these and other aspects of the error data was that they were attributable to internal noise that acted primarily to make same pairs look different.

The primary problem with Krueger and Shapiro's (1982) study is that, although the authors interpret their results in terms of internal noise, the experiments involve extraneous noise. That is, the pairs in a list other than the particular one that is being judged as same or different at any moment represent extraneous noise stimuli. To the extent that subjects cannot exclude them from the decision process, they will influence the judgments.

Studies that have employed simultaneous noise letters have clearly shown that they cannot be ignored. Rather, they have very systematic effects on target identification (B. A. Eriksen \& C. W. Eriksen, 1974; C. W. Eriksen \& B. A. Eriksen, 1979; C. W. Eriksen \& Schultz, 1979), as well as on letter matching (C. W. Eriksen, O'Hara, \& B. A. Eriksen, 1982; Keren, O'Hara, \& Skelton, 1977). Such noise stimuli also have effects when they precede the targets by $500 \mathrm{msec}$ or less (C. W. Eriksen \& B. A. Eriksen, 1979; Proctor, 1981; Taylor, 1977). From their own experiments, Krueger and Shapiro (1982) concluded that "when pairs are presented in close temporal and spatial proximity, subjects cannot avoid making and relying on extraneous interpair comparisons in addition to the relevant intrapair comparisons"' (p. 491).

Although Krueger and Shapiro (1982) acknowledged that extraneous letters were included in the comparison process, they apparently did not fully appreciate the extent to which this factor is crucial to their results. They stated, "The interpair factor does not directly affect the error predictions of the noisyoperator theory. It deals with which type of list ought to do better, not with the relative change or crossover (i.e., on false alarms vs. misses) between list types" (p. 491). Contrary to their statement, however, the general pattern of errors that they obtained is apparently attributable to the interpair factor, rather than to internal noise.

Extraneous noise letters influence match reaction time in the following manner (see C. W. Eriksen et al., 1982; Keren et al., 1977; Krueger \& Shapiro, 1980; O'Hara, 1980; O'Hara \& C. W. Eriksen, 1979). Reaction time and errors to same pairs increase greatly when the noise letters are different from the relevant pair, whereas reaction time and errors to different pairs increase when the noise letters are the same as one member of the relevant pair. This latter effect of noise on different pairs also seems to be of somewhat lesser magnitude than the former effect on same pairs (Keren et al., 1977; Krueger \& Shapiro, 1980).

The primary finding of Krueger and Shapiro (1982) that misses of a target pair predominate in different lists, whereas false-alarms predominate in same lists, indicates that subjects were tending to misperceive same letter pairs as different. That effects of noise stimuli are greater for same pairs than for different pairs can, to a large extent, account for this finding. Moreover, a detailed examination of the specific list structures in Krueger and Shapiro's experiments indicates that the interpair relationships are such as to cause same pairs to be misperceived as different rather than vice versa.

Krueger and Shapiro (1982) used lists constructed from five letters in which the percentage of interpair repetitions was $0 \%$ and lists constructed from two letters in which the percentage of interpair repetitions was $50 \%$. For different lists, each nontarget different pair is preceded by two different letters when repetition is $0 \%$, whereas when repetition is $50 \%$, the two noise letters from the previous pair are each the same as one of the relevant letters and different from the other. In either case, there should be little tendency to misperceive different pairs as same (i.e., to make false alarms). Moreover, the critical same pair in these lists would be preceded by either two letters $(0 \%$ repetition condition) or one letter ( $50 \%$ repetition condition) that differed from the target pair. These mismatching letters would produce a tendency to miss the critical same pair. Thus, the influence of the interpair extraneous stimuli would be to produce a predominance of misses for different lists.

For same lists, the noncritical same letter pairs are all preceded by a different same pair when repetition is $0 \%$, whereas only half of them are when repetition is $50 \%$. The extraneous letters should, thus, produce a much greater tendency toward false alarms with $0 \%$ repetition than with $50 \%$ repetition. Krueger and Shapiro (1982) obtained approximately three times as many false alarms in the former condition than in the latter. With $0 \%$ repetition, the critical different pair would always be preceded by a same pair composed of a different letter from those of the critical pair, whereas with $50 \%$ repetition, the letters of the preceding same pair would be different from one of the letters of the critical pair. Keren et al. (1977) have shown that when two noise letters with relationships comparable to those above are employed in physicalmatch situations (as in Experiments 1 and 2 of Krueger and Shapiro, 1982), the effect on processing of different pairs is slight relative to that for same pairs.

In summary, there is no need to invoke the internal- 
noise principle of the noisy-operator theory to account for the major aspects of Krueger and Shapiro's (1982) error data. The tendency to make false alarms for same lists, but misses for different lists, is apparently attributable solely to the inclusion of extraneous letters in the comparison process.

The evidence that Krueger and Shapiro (1982) provided in support of the rechecking postulate was the failure to obtain a preponderance of false alarms for same lists when all pairs were presented simultaneously (Experiment 1). They concluded that whenever subjects thought that they had found a different pair, they rechecked the pair. Rapid serial presentation was employed in Experiments 2 and 3 to eliminate this rechecking, and the predicted tendency to false alarms became evident.

Given the very low proportion of false alarms with simultaneous presentation, combined with the high proportion of false alarms with sequential presentation, the conclusion that subjects rechecked potential critical pairs in the simultaneous condition seems reasonable. To argue that the rechecking involved in this situation supports the rechecking postulate of the noisy-operator theory is much more questionable. The evidence for rechecking was obtained under conditions of extraneous noise in which 12 pairs of letters were viewed simultaneously. Because searching for the target pair in this situation is difficult, taking a "second look" at potential targets is understandable. However, the noisy-operator theory says that rechecking is performed for singly presented pairs in nonnoisy situations. The evidence for rechecking that Krueger and Shapiro (1982) obtained is not analytic to this latter issue. The more direct tests of the rechecking postulate of the noisy-operator theory conducted in Experiments 1 and 2 of the present article indicate that rechecking of sensory information is not the basis of the same-different disparity.

\section{External Noise}

Krueger (1978) assumed that the degree of difference was equivalent for all different letter pairs. This assumption of homogeneity of difference is critical to the prediction of the same-different disparity by the noisy-operator theory in that if heterogeneity of difference is present, it will tend to counteract the effect of internal noise (Krueger, 1978, 1979).

Proctor and Rao (1983) indicated that studies of confusions in letter identification, as well as studies examining the influence of similarity on different reaction times, contradict the assumption of homogeneity of difference (Clement \& Carpenter, 1970; Gilmore et al., 1979; Thorson et al., 1976). Experiment 3 of the present article confirms the previous findings. Different reaction times varied systematically with similarity.

The primary purpose of Experiment 3 was, how- ever, to manipulate the magnitude of heterogeneity of difference present in two different letter sets to determine whether it has the effect on the samedifferent disparity predicted by the noisy-operator theory. Contrary to prediction, the heterogeneity manipulation had no reliable effect on the magnitude of the disparity. This null effect was obtained even though the heterogeneity manipulation had the desired effect of producing greater variability in reaction time between different pairs within the more heterogeneous set than within the more homogeneous one. Thus, not only is the homogeneity-of-difference assumption invalid, but also manipulation of heterogeneity of difference does not have the effect on the same-different disparity predicted by the noisyoperator theory.

\section{Inhibition Principle}

Although the primary purpose of the experiments reported in this article was to test predictions of the noisy-operator theory, which were not upheld, predictions can also be made from the inhibition viewpoints of Proctor (1981) and C. W. Eriksen et al. (1982). Proctor attributes the slower different judgments to competition of internal recognition responses, whereas Eriksen et al. attribute them to competition at the overt response level attributable to similarities between the two letters. ${ }^{2}$ Both accounts make similar predictions for the present experiments.

Because neither account relies on rechecking of sensory information, no effect of exposure duration is predicted as long as there is sufficient time for a clean encoding to be made. Thus, both viewpoints predict the null effects of exposure duration obtained in the present experiments.

The same-different disparity in reaction time would also be expected to be independent of the amount of heterogeneity of difference present in the letter set. That is, the critical factor determining the relative difference in mean same and different reaction times would be the mean difference between letter pairs, not the variability of the difference. In Experiment 3, the two letter sets were equated as closely as possible for mean difference, and the same-different disparity was of approximately the same magnitude for the two letter sets. Thus, in addition to providing evidence against the noisy-operator theory, the results obtained in the present expetiments are generally consistent with the inhibition principle.

\section{Fundamental Process or Response Bias}

The internal-noise and inhibition accounts of the same-different disparity in reaction time both regard the disparity as reflecting a fundamental property of the human information-processing system. In contrast, Ratcliff and Hacker $(1981,1982)$ have recently argued that the same-different disparity reflects only 
response bias. We (Proctor \& Rao, 1982) have argued that such is not the case. The primary evidence against a response bias interpretation of the same-different disparity is the fact that false same errors do not generally outnumber false different errors (Krueger, 1978; Krueger \& Shapiro, 1981). The present study emphasizes that point. Collapsed across experiments, the mean proportion of errors for same and different pairs was an identical .0192 . Thus, although bias may be a major factor with multiletter strings, it is not the primary basis for the same-different disparity obtained with single letter pairs. Rather, this disparity apparently reflects a fundamental process, be it inhibition, internal noise, or some other factor, that must be explained. The blanket statement of Ratcliff and Hacker (1982) that "models should not place too much weight on the difference between reaction time for positive and negative responses as an absolute measure of processing"' (p. 604) is unwarranted.

\section{REFERENCE NOTE}

1. Gibson, E. J., Osser, H., Schiff, W., \& Smith, J. An analysis of critical features of letters, tested by a confusion matrix. In $A$ basic research program on reading (Cooperative Research Project No. 639). Washington, D.C: U.S. Office of Education, 1963.

\section{REFERENCES}

Clement, D. E., \& Carpenter, J. S. Relative discriminability of visually presented letter pairs using a same-different choice reaction time task. Psychonomic Science, 1970, 20, 363-364.

Eriksen, B. A., \& Eriksen, C. W. Effect of noise letters upon the identification of a target letter in a nonsearch task. Perception \& Psychophysics, 1974, 16, 143-149.

ERIRsen, C. W. The use of a visual mask may seriously confound your experiment. Perception \& Psychophysics, 1980, 28, 89-92.

Eriksen, C. W., \& Eriksen, B. A. Target redundancy in visual search: Do repetitions of the target within the display impair processing? Perception \& Psychophysics, 1979, 26, 195-205.

Eriksen, C. W., O'Hara, W. P., \& Eriksen, B. A. Response competition effects in same-different judgments. Perception \& Psychophysics, 1982, 32, 261-270.

ERIKsen, C. W., \& Schultz, D. W. Information processing in visual search: A continuous flow conception and experimental results. Perception \& Psychophysics, 1979, 25, 249-263.

Geyer, L. H., \& Dewald, C. G. Feature lists and confusion matrices. Perception \& Psychophysics, 1973, 14, 471-482.

Gibson, E. Principles of perceptual learning and development. New York: Appleton-Century-Crofts, 1969.

Gilmore, G. C., Hersh, A., Caramazza, A., \& Griffin, J. Multidimensional letter similarity derived from recognition errors. Perception \& Psychophysics, 1979, 25, 425-431.

Keren, G., \& BAGgen, S. Recognition models of alphanumeric characters. Perception \& Psychophysics, 1981, 29, 234-246.

Keren, G., O'HarA, W. P., \& Skelton, J. M. Levels of noise processing and attentional control. Journal of Experimental Psychology: Human Perception and Performance, 1977, 3, 653-664.

Krueger, L. E. A theory of perceptual matching. Psychological Review, 1978, 85, 278-304.

KRUEGER, L. E. A model of unidimensional perceptual matching.
Journal of Experimental Psychology: Human Perception and Performance, 1979, 5, 277-288.

Krueger, L. E., \& Shapiro, R. G. Repeating the target neither speeds nor slows its detection: Evidence for independent channels in letter processing. Perception \& Psychophysics, 1980, 28, 68-76.

Krueger, L. E., \& Shapiro, R. G. A reformulation of Proctor's unified theory for matching-task phenomena. Psychological Review, 1981, 88, 573-581.

Krueger, L. E., \& Shapiro, R. G. Search for a matching or mismatching letter pair. Perception \& Psychophysics, 1982, 31, 484-492.

Lindsay, P. H., \& Nonman, D. A. Human information processing: An introduction to psychology (2nd ed.). New York: Academic Press, 1977.

O'Harn, W. P. Evidence in support of word unitization. Perception \& Psychophysics, 1980, 27, 390-402.

O'Hara, W., \& ERiksen, C. W. Word unitization examined using an interference paradigm. Bulletin of the Psychonomic Society, 1979, 14, 81-84.

Proctor, R. W. A unified theory for matching-task phenomena. Psychological Review, 1981, 88, 291-326.

Proctor, R. W., \& Fagnani, C. A. Effects of distractor-stimulus modality in the Brown-Peterson distractor task. Journal of Experimental Psychology: Human Learning and Memory, 1978, 4, 676-684.

Proctor, R. W., \& RAo, K. V. On the "misguided" use of reaction-time differences: $A$ discussion of Ratcliff and Hacker (1981). Perception \& Psychophysics, 1982, 31, 601-602.

Proctor, R. W., \& R^o, K. V. Reinstating the original principles of Proctor's unified theory for matching-task phenomena: An evaluation of Krueger and Shapiro's reformulation. Psychological Review, 1983, 90, 21-37.

RATCLIFF, R., \& HACKER, M. J. Speed and accuracy of same and different responses in perceptual matching. Perception \& Psychophysics, 1981, 30, 303-307.

RATCLIFT, R., \& HACKER, M. J. On the misguided use of reactiontime differences: A reply to Proctor and Rao (1982). Perception \& Psychophysics, 1982, 31, 603-604.

Schultz, D. W., \& Eriksen, C. W. Do noise masks terminate target processing? Memory \& Cognition, 1977, 5, 90-96.

TAYLOR, D. A. Time course of context effects. Journal of Experimental Psychology: General, 1977, 106, 404-426.

Thorson, G., Hochraus, L., \& Stanners, R. F. Temporal changes in visual and acoustic codes in a letter-matching task. Perceptual \& Psychophysics, 1976, 19, 346-348.

TownsEND, J. T. Theoretical analysis of an alphabetic confusion matrix. Perception \& Psychophysics, 1971, 9, 40-50.

\section{NOTES}

1. If rechecking is eliminated, only a single decision criterion would be employed on the perceived difference dimension. The prediction that the elimination of rechecking will result primarily in an increase of false different errors assumes a low criterion (i.e., subjects will respond different if any appreciable difference is perceived). A higher setting of the criterion would not produce this pattern of results. Because Krueger and Shapiro (1982) consider the prediction of relatively greater false different errors when rechecking is eliminated to be valid, we will regard it as such.

2. Proctor (1981) based his concept of inhibition on competition between name codes that slowed identification and comparison of different pairs. Proctor and Rao (1983) have indicated generally how this inhibition could also apply to comparisons based on physical codes, as in the present experiments. We are currently developing a more specific account of this process.

(Manuscript received September 3, 1982; revision accepted for publication November 20, 1982.) 